\title{
LITERATUR REVIEW : APLIKASI TERAPI HAN (HIPNOTIS, AKTIFITAS FISIK, NUTRISI) PADA KELUARGA ANAK USIA SEKOLAH DENGAN OBESITAS
}

\author{
*Irma Darmawati \\ * Sekolah Tinggi Ilmu Keperawatan PPNI Jawa Barat \\ Jl. Muhammad No. 34A Bandung 40173 \\ Telp. 022-6004498, 022-6121914, Fax.022-6121914 \\ Email : irma_darmawati87@yahoo.com
}

\begin{abstract}
Abstrak
Tingginya angka kejadian obesitas pada anak usia sekolah di Indonesia disebabkan oleh adanya perubahan pola makan makanan cepat saji dan adanya perkembangan teknologi sebagai salah satu gaya hidup baru yang justru dapat menurunkan aktifitas anak. Optimalisasi peran keluarga menjadi sangat penting, karena keluarga adalah rumah pertama tempat anak belajar hidup sehat. Melalui upaya pemberian asuhan keperawatan keluarga diharapkan dapat mengelola masalah keluarga salah satunya pada anak usia sekolah. Pencarian literatur dilakukan dengan mencari kesamaan (compare), mencari ketidaksamaan (contrass), memberikan pandangan (criticize), membandingkan (synthesize), serta meringkas (summarize) materi-materi yang berkaitan dengan terapi yang dapat dilakukan pada anak usia sekolah dengan masalah obesitas dari berbagai bahan rujukan dengan rentang waktu penerbitan 2006-2015. Terapi HAN (Hipnosis, Aktivitas fisik, Nutrisi) dapat diterapkan dalam proses asuhan keperawatan bagi keluarga binaan perawat dengan tujuan utama perubahan perilaku hidup sehat yang menunjang pada upaya pencapaian berat badan ideal bagi anak dan keluarga dengan masalah obesitas. Pendekatan terapi yang pertama, hipnosis dilakukan untuk memberikan sugesti positif pada anak terkait tubuh ideal dan pola hidup sehat. Pendekatan terapi yang kedua adalah terapi aktivitas fisik pada anak. Pendekatan terapi yang ketiga adalah terapi nutrisi. Terapi nutrisi ini dilakukan melalui pola makan food combining yang merupakan cara atau pola konsumsi makanan dengan memperhatikan jenis bahan makanan yang selaras sehingga dapat mengoptimalkan pencernaan dan penyerapan zat makanan. Penerapan terapi HAN ini dapat dijadikan sebagai inovasi perawat puskesmas yang akan melaksanakan kunjungan rumah sehingga dapat mengendalikan angka kejadian obesitas pada anak usia sekolah.
\end{abstract}

Kata kunci: Anak usia sekolah, Obesitas, Hipnosis, Aktifitas fisik, Nutrisi

\begin{abstract}
Increasing incidence of obesity in Indonesian school age children are caused by changes in fast food diet and technology development as a new lifestyle that can reduce the activity. Optimalization family role through family nursing care is expected can manage a family problem about obesity. Literature searched done by looking for similarities (compare), seeking inequality (contrass), providing a view (criticize), comparing (synthesize), as well as summarizing (summarize) materials related to therapy that can be performed on children ages school with obesity problem with literature source from 2006 to 2014 publication. HAN therapy (Hypnosis, physical activity, nutrition) can be applied in the process of nursing care for nurses assisted the family with the main purpose of healthy behavior changes that support the efforts to achieve the ideal weight for children and families with problems of obesity. The first therapy, hypnosis performed to give positive suggestions in children associated ideal body and a healthy lifestyle. The second therapy is the treatment of physical activity in children. The third therapy is a nutritional therapy, nutritional therapy is done through food combining diet. Application of HAN therapy can be used as a Puskesmas innovations in home visits to help and support the good quality of indonesia people in the future.
\end{abstract}

Keywords: School Age Children, Obesity, Hypnosis, Physical activity, Nutrition 


\section{PENDAHULUAN}

Organisation for Economic Co-operation and Development (OECD) (2014) menyebutkan bahwa satu dari lima anak usia sekolah di seluruh dunia mengalami obesitas. Prediksi pada tahun 2050 , obesitas akan terjadi pada $60 \%$ agregat anak usia sekolah di dunia (Reilly, 2009 dalam Cullen, 2011). Data ini didukung oleh kemenkes (2013) melalui laporan riset kesehatan dasar yang menyebutkan bahwa prevalensi kejadian kelebihan berat badan pada anak usia sekolah adalah $18,8 \%$ dan mengalami peningkatan dua kali lipat dibandingkan prevalensi pada tahun 2010 dengan tingkat prevalensi tertinggi terjadi pada anak usia sekolah di kawasan DKI Jakarta dengan $30,1 \%$ angka kejadian kelebihan berat badan. Prevalensi cukup tinggi pula di wilayah Jawa Barat termasuk kota Depok salah satunya sebagai wilayah yang berbatasan langsung dengan wilayah DKI Jakarta dengan prevalensi hampir sama dengan prevalensi nasional di kisaran angka $18 \%$ yang juga menunjukkan peningkatan signifikan dari dari tahun 2010 sebesar 8,5\%.

Saat anak beranjak dewasa, obesitas berisiko membawa gangguan kesehatan dan akan berpotensi pada gangguan metabolisme glukosa dalam tubuh dan perkembangan penyakit kronis seperti jantung, penyumbatan pembuluh darah dan lain-lain (Jones, 2010). Sjarif (2004) juga menjelaskan bahwa obesitas pada anak usia sekolah juga dapat menurunkan tingkat kecerdasan karena aktivitas dan kreativitas anak menjadi menurun dan anak cenderung malas akibat kelebihan berat badan. Ancaman kesehatan yang dapat terjadi pada anak usia sekolah ini sebaiknya dijadikan sorotan penting bagi perawat komunitas dalam menjalankan fungsinya sebagai pelaksana asuhan keperawatan dan juga edukator untuk melakukan intervensi terhadap individu dan keluarga anak usia sekolah dengan pemberian intervensi keperawatan berbasis pada penyebab masalah obesitas yang utama pada anak usia sekolah.

Data hasil pengkajian praktik komunitas di MI Nurul Fallah sebagai salah satu sekolah dengan prevalensi AUS obesitas sebesar 24\% menunjukkan bahwa sebanyak 50\% anak mengonsumsi makanan cepat saji dan kurang mengonsumsi buah dan sayur pada $72 \%$ anak. Obesitas pun dapat dipicu oleh kebiasaan konsumsi susu formula yang diberikan ibu ketika anak balita dengan jumlah asupan yang melebihi porsi yang dibutuhkan oleh balita (Stettler dkk, 2002). Obesitas saat balita kemudian berkembang dan terbawa sampai anak tetap obesitas di masa usia sekolah. Selain itu banyaknya anggapan bahwa anak yang mengalami obesitas dan obesitas adalah anak yang sehat, lucu dan menggemaskan semakin menambah risiko peningkatan angka kejadian obesitas pada anak, pada kenyataannya anak dengan obesitas mengalami proses perubahan nutrisi yang bisa menyebabkan masalah kesehatan untuk anak tersebut pada saat ini ataupun untuk beberapa tahun kedepan. Dapat disimpulkan bahwa semua kebiasaan pola hidup dan persepsi dalam keluarga terhadap anak obesitas memegang peran penting dalam peningkatan prevalensi anak dengan obesitas.

La Rocca (2009) menyebutkan bahwa peran genetik dalam keluarga memengaruhi status obesitas sebesar 5-25\% pada anak. Faktor lainnnya yang berkontribusi dalam keluarga adalah kebiasaan pola makan di rumah, aktivitas fisik sehari-hari,budaya menonton televisi, dan hubungan orang tua dengan anak. Institute of medicine dalam La Rocca (2009) menyebutkna bahwa orang tua dan pengasuh anak di rumah memiliki pengaruh yang kuat dalam membentuk kebiasaan kesehatan pada anak secara dini. Jika upaya pola hidup sehat tidak diterapkan dalam keluarga, maka risiko kesehatan pada seluruh keluarga menjadi meningkat. Anak yang obesitas sebagian besar memiliki orang tua dengan status gizi yang sama, yakni overweight atau obesitas (Keller, 2008). La Rocca (2009) menyimpulkan bahwa keluarga terutama ibu adalah kunci dan pintu utama untuk mengurangi risiko overweight atau obesitas pada seluruh anggota keluarga, karena terkait dengan upaya perubahan pola hidup yang dapat distimulasi oleh ibu di keluarga terkait penyediaan makan di rumah, pengaturan aktifitas fisik anak, dan hubungan antara ibu dan anak. 
Fungsi utama keluarga terkait dengan pengelolaan obesitas anak usia sekolah adalah fungsi afektif dan perawatan kesehatan. Fungsi afektif mencakup seberapa jauh ibu dan anggota keluarga lainnya mampu melakukan pengelolaan masalah obesitas di rumah dengan penuh dukungan positif, perhatian serta menjadi panutan yang baik dalam proses perubahan perilaku. Selanjutnya fungsi perawatan kesehatan keluarga khususnya ibu dalam mengenal masalah obesitas, memahami risiko kesehatan yang akan dialami anak, dan sejauh mana keluarga termotivasi untuk melakukan perubahan perilaku menjadi pola hidup sehat pada anak dan juga pada seluruh anggota keluarga secara umum.

Upaya preventif yang dapat dilakukan pada anak usia sekolah dengan obesitas berfokus pada upaya perubahan perilaku terkait pola hidup anak yang dapat distimulasi oleh pendekatan perubahan pola hidup secara tidak langsung oleh orang tua terhadap anak. Upaya preventif ini dibuat menjadi sebuah inovasi penatalaksanaan obesitas di keluarga bernama Terapi HAN (Hipnosis, Aktivitas fisik, Nutrisi) yang pada pelaksanaannya dilakukan melalui peran orang tua yang seharihari dalam menyediakan makan anak, juga ikut terlibat dalam aktivitas anak sehari-hari, serta melalui hubungan komunikasi personal antara ibu dan anak melalui hipnosis yang diberikan dengan cara berkomunikasi secara asertif dengan anak. Kombinasi ketiga pendekatan ini diharapkan dapat merubah pola hidup anak yang secara perlahan akan mampu menurunkan berat badan anak dan memperbaiki status gizi anak menjadi ideal. Kombinasi ketiga terapi ini belum umum dilakukan oleh perawat dalam penatalaksanaan obesitas di keluarga. Pendekatan selama ini masih berfokus pada pengelolaan nutrisi dan aktifitas fisik dengan berbagai variasi jenis pengaturan nutrisi dan aktifitas fisik. Upaya penulis selaku perawat dalam hal ini bermaksud untuk menggabungkan ketiga terapi yang mampu mendukung anak merubah perilaku dengan pendekatan secara fisik dan secara psikologis. Diharapkan dapat terjadi perubahan perilaku yang bisa mendukung penurunan berat badan yang juga berkorelasi dengan penurunan risiko kesehatan.

\section{METODE PENCARIAN}

Artikel dibuat dengan melakukan proses pencarian literatur dengan mencari kesamaan (compare), mencari ketidaksamaan (contrass), memberikan pandangan (criticize), membandingkan (synthesize), serta meringkas (summarize) materi-materi yang berkaitan dengan terapi yang dapat dilakukan pada anak usia sekolah dengan masalah obesitas dari berbagai bahan rujukan dengan rentang waktu penerbitan 2006-2014.

\section{PEMBAHASAN}

Terapi HAN (Hipnosis, Aktivitas fisik, Nutrisi) dapat diterapkan dalam proses asuhan keperawatan bagi keluarga binaan perawat dengan tujuan utama perubahan perilaku hidup sehat yang menunjang pada upaya pencapaian berat badan ideal bagi anak dan keluarga dengan masalah obesitas.

Pendekatan terapi yang pertama, hipnosis dilakukan untuk memberikan sugesti positif pada anak terkait tubuh ideal dan pola hidup sehat. Barabasz dan Spiegel (1989) melakukan penelitian terkait intervensi hipnotis terhadap 45 orang obesitas yang dibagi dalam 3 kelompok perlakuan dengan pemantauan perilaku selama 3 bulan. Kelompok pertama diberikan perlakuan pendidikan kesehatan untuk melaksanakan pengaturan nutrisi selama 90 hari. Kelompok kedua diberikan intervensi hipnosis untuk pengaturan berat badan. Hipnosis yang diberikan adalah hipnosis dari Spiegel dan Spiegel (1978, dalam Barabasz \& Spiegel, 1989) dengan melakukan hipnosis terhadap diri sendiri dengan sering sering mengucapkan pada diri sendiri : 1 . Kebanyakan makan adalah racun bagi tubuh saya, 2. Saya butuh tubuh untuk hidup, 3. Saya berhutang perhatian dan penjagaan terhadap tubuh saya. Self hypnosis ini dilafalkan setiap hari oleh kelompok perlakuan kedua. Selanjutnya kelompok perlakuan ketiga diberikan intervensi yang sama dengan kelompok kedua,namun kalimat pertama kebanyakan makan adalah racun bagi tubuh saya diganti dengan kata-kata makanan 
kesukaan menjadi misalnya: kebanyakan makan kentang goreng adalah racun bagi tubuh saya, atau contoh lainnya kebanyakan makan burger adalah racun bagi tubuh saya. Hasil penelitian menunjukan efek yang signifikan pada kelompok 2 dan 3 dalam perubahan perilaku makan dengan rata-rata penurunan berat badan sebanyak $3,4 \mathrm{~kg}$ dalam jangka waktu 3 bulan jia dibandingkan dengan penurunan berat badan sebesar $1,3 \mathrm{Kg}$ pada kelompok perlakuan pertama. Hal ini selaras dengan penelitian oleh Anderson (1985, dalam Barabasz \& Spiegel, 1989) terhadap 61 responden yang diberikan intervensi self hypnosis mampu meningkatkan kewaspadaan dan meningkatkan motivasi untuk merubah perilaku makan dan olahraga yang dapat mendukung penurunan berat badan pada responden.

Hipnosis sebagai kekuatan sugesti dapat menjadi memori jangka panjang bagi perubahan perilaku anak (Gromm, 1992 dalam Sapp, Obiakor, Scholze, \& Gregas (2007). Dalam studi meta analisis oleh Sapp, Obiakor, Scholze, dan Gregas (2007) terhadap sampel sejumlah 577 yang terbagi dalam 2 kelompok, yakni kelompok 1 dengan pemberian cognitive behaviour therapy dan kelompok 2 dengan pemberian hipnosis bersama cognitive behaviour therapy. Hasil pada kelompok 2 menunjukan hasil dan efek yang lebih signifikan terhadap penurunan berat badan. Sapp, Obiakor, Scholze, dan Gregas (2007) melakukan meta analisis terhadap 10 penelitian yang memberikan intervensi hipnosis dalam upaya penurunan berat badan menyimpulkan bahwa hipnosis terbukti efektif dalam meningkatkan motivasi dan manajemen diri dalam pengelolaan berat badan sehingga mampu mendukung nilai penurunan berat badan pada klien dengan obesitas.

Kekuatan sugesti positif melalui hipnosis ini cocok diterapkan pada semua umur termasuk anak usia sekolah (Kohen \& Olness, 2011). Perbedaan usia hanya membedakan jenis kalimat sugesti yang akan diberikan. Haber, Nitkin dan Shenker (1979, dalam Kohen \& Olness, (2011) melakukan hipnosis terhadap remaja dan mengarahkan sugesti positif ke arah pemilihan makanan, olahraga, dan peningkatan harga diri. Selajutnya penelitian terkait hipnosis yang dilakukan pada 505 anak usia sekolah obesitas, dilaporkan bahwa mereka mampu menurunkan berat badan selama penelitian. Sugesti spesifik yang diberikan adalah untuk menikmati makanan yang dikonsumsi namun tetap sesuai jumlah porsi yang dianjurkan, menikmati waktu makan tanpa ngemil berlebihan, membayangkan diri menjadi lebih langsing, membayangkan tubuh seseorang yang diidolakan. Self hypnosis ini diucapkan selama beberapa kali dalam sehari selama jangka waktu yang diinginkan.

Gabriel (2008) menciptakan sebuah inovasi bernama the gabriel methode yang menerapkan dan menjelaskan self hypnosis untuk menurunkan berat badan secara berkala. Metode ini memfokuskan pada pemusatan fikiran agar memiliki mental berat badan ideal. Menurutnya selama ini orang orang dengan obesitas berada pada posisi merasa aman dengan badannya yang gemuk sehingga secara tidak langsung otak akan memerintahkan tubuh untu tetap dan bertambah semakin gemuk, dikarenakan perasaan nyaman dari individu untuk gemuk. Melalui metode ini klien dirubah persepsinya untuk berfikir bahwa gemuk itu tidak aman dan menimbulkan banyak penyakit, tubuh yang ideal lah yang aman bagi kita. Selain itu dalam metode ini dijelaskan bahwa ada keterkaitan sugesti visualisasi bentuk tubuh ideal kita terhadap motivasi perubahan perilaku yang sejalan dengan hasil-hasil penelitian sebelumnya. Pendekatan bulan pertama dalam metode ini dimulai dari visualisasi bentuk tubuh ideal dan bayangan makanan yang baik bagi tubuh dan makanan sampah bagi tubuh, dilakukan setiap hari sebelum tidur dan ketika bangun tidur. Kemudian dilanjutkan dengan mensugesti diri dengan keyakinan merasa aman dengan tubuh ideal, pejamkan mata, dan bayangkan seluruh energi positif mengalir di setiap ruas tubuh klien. Energi positif inilah yang mampu meningkatkan motivasi dan keyakinan diri untuk menjadi lebih baik dengan berat badan ideal setiap hari (Gabriel, 2008).

Pendekatan terapi yang kedua adalah terapi aktivitas fisik pada anak. Terapi aktivitas fisik harus dilakukan karena kurangnya aktivitas fisik 
dapat menjadi salah satu penyebab obesitas pada anak (NIH, 2014). Studi kohort yang dilakukan oleh Brien, Katzmarzyk, Craig, dan Gauvin (2007) juga mendukung pernyataan gaya hidup kurang gerak dengan aktifitas fisik ringan dapat menjadi faktor penentu kejadian obesitas. Terapi aktifitas fisik ini ditujukan untuk mengoptimalkan aktivitas anak sehari-hari dari tidak beraktifitas atau aktifitas fisik ringan menjadi beraktifitas fisik sedang. Sigal, Kenny, Wasserman, Sceppa, dan White (2006) menyatakan bahwa optimalisasi aktifitas fisik memiliki kemungkinan yang tinggi untuk menurunkan berat badan. Hal ini didukung oleh penelitian Ross, et al., (2004) yang membagi kelompok dengan empat kelompok berbeda, kelompok latihan fisik untuk menurunkan berat badan, kelompok latihan dengan aktifitas fisik ringan, kelompok pembatasan kalori, serta kelompok kontrol tanpa pembatasan kalori dan latihan fisik. Kelompok-kelompok ini diuji dan disimpulkan bahwa optimalisasi aktifitas fisik merupakan strategi yang paling efektif untuk mengurangi total lemak tubuh, lemak perut, dan lemak pada jaringan visceral.

White House Task Force on Childhood Obesity (2010) merekomendasikan jenis latihan fisik daya tahan tubuh (endurance exercise) sebagai upaya menurunkan berat badan bagi anak usia sekolah. Hal ini sejalan dengan Dewantari, Kayanaya, dan Melantini (2011) yang menyimpulkan bahwa latihan fisik jenis daya tahan tubuh merupakan metode ideal untuk mengurangi massa jaringan lemak dan menurunkan berat badan. Anam (2010) melakukan penelitian terhadap 21 responden di Semarang. Intervensi yang diberikan berupa latihan daya tahan tubuh dalam bentuk lari selama 20 menit dan senam selama 10 menit dengan durasi 3x/ minggu mampu memberikan perubahan bermakna terhadap IMT responden pada sebelum dan sesudah penelitian dengan nilai pvalue $=0,036$.

Wijayanti (2013) melakukan intervensi latihan fisik daya tahan tubuh berupa latihan aerobik selama 4 minggu terhadap 28 remaja, hasil penelitian menunjukan bahwa ada perbedaan bermakna yang menunjukan latihan aerobik sebagai latihan yang mampu menurunkan berat badan klien. Sebuah penelitian mendapatkan hasil bahwa intervensi olahraga daya tahan tubuh selama 12 minggu (sepeda statis 30 menit, 3 kali seminggu), terbukti secara signifikan memperbaiki kadar LDL, HDL, kolesterol total dan rasio LDL/HDL. Penelitian ini dilakukan terhadap 88 anak pada pelajaran olahraga selama satu semester, menghasilkan data efek positif terhadap tekanan darah (Tolfrey, Campbell , \& Batterham , 1998). Anam (2010) melakukan penelitian terhadap 21 anak usia sekolah di Semarang dapat membuktikan juga bahwa latihan fisik jenis daya tahan tubuh berupa lari, basket, dan senam mampu menurunkan berat badan anak usia sekolah dan sesuai dengan kemampuan anak.

Penelitian lainnya yang mendukung peran latihan daya tahan tubuh dalam upaya penurunan berat badan adalah modifikasi dari latihan lari yang diselang seling dengan masa istirahat aktif yang disebut latihan interval training. Green, Campbel, \& Wallman (2010), menyatakan bahwa latihan interval training lebih menurunkan berat badan dibandingkan dengan latihan lari yang dilakukan terus menerus (continuous training). Dapat disimpulkan bahwa jenis latihan fisik yang mendukung penurunan berat badan adalah latihan fisik jenis daya tahan tubuh yang dilakukan secara interval training. Jenis latihan interval training dapat dilakukan oleh keluarga adalah olahraga dalam bentuk berjalan kaki, lari, bersepeda, aerobik, senam dan lainnya, dengan catatan latihan dilakukan secara selang seling pada masa istirahat dan masa aktifnya (ACSM, 2014).

Pendekatan terapi yang ketiga adalah terapi nutrisi. Terapi nutrisi ini dilakukan melalui pola makan food combining yang merupakan cara atau pola konsumsi makanan dengan memperhatikan jenis bahan makanan yang selaras sehingga dapat mengoptimalkan pencernaan dan penyerapan zat makanan (Lebag, 2013). Food combining bertujuan agar proses pencernaan makanan, penyerapan sari makanan, pemanfaatannya untuk tubuh, dan pembuangan sampah makanan berlangsung efektif dan efisien. Dengan demikian, seluruh organ tubuh dapat bekerja sesuai kapasitasnya, dan tidak kelebihan beban kerja. Beban kerja yang berlebihan, akan mengakibatkan kelelahan pada organ tubuh yang kemudian 
berimbas pada meningkatnya kadar gula darah (akibat radang pankreas) atau kolesterol/ trigliserida darah (gangguan pada empedu).

Penatalaksanaan obesitas pada anak memerlukan kerjasama dan keterlibatan seluruh anggota keluarga. Prinsip penatalaksanaannya harus tetap mempertimbangkan faktor tumbuh kembang yang masih terus berlangsung sampai masa remaja. Penatalaksanaan terapi HAN pada keluarga didampingi oleh perawat sehingga implementasi terapi HAN yang ditujukan untuk menurunkan berat badan anak dan juga meningkatkan kualitas hidup anak dengan optimalisasi tumbuh kembang anak tanpa risiko kesehatan yang diakibatkan masalah obesitas di masa yang akan datang. Penerapan ketiga terapi ini didahului dengan promosi kesehatan terkait gizi dan aktifitas fisik yang dibutuhkan oleh aus yang obesitas. Selanjutnya AUS diberikan penjelasan dan demonstrasi self hypnosis untuk meningkatkan motivasi meningkatkan aktifitas fisik dan pengelolaan nutrisi. Dalam self hypnosis anak diminta berada dalam kondisi rileks, memejamkan mata dan membayangkan bentuk tubuh ideal yang diharapkan anak setiap sebelum tidur dan saat bangun tidur. Selanjutnya anak diminta melakukan hipnosis terhadap diri sendiri dengan sering sering mengucapkan pada diri sendiri: 1. Makan sayur dan buah membuat tubuh sehat dan kuat 2. Kebanyakan makan yang manis dan berminyak adalah racun bagi tubuh saya, 3. Saya akan beraktivitas sampai berkeringat agar sehat.

Penatalaksanaan selanjutnya adalah terapi aktivitas fisik. Setelah anak diberikan pendidikan kesehatan dan juga self hypnosis selanjutnya anak diminta menyepakati 1 jenis latihan fisik daya tahan tubuh yang disukai anak. Jenis latihan interval training dapat dilakukan oleh keluarga adalah olahraga dalam bentuk berjalan kaki, lari, bersepeda, aerobik, senam dan lainnya. Misalnya anak menyukai bermain sepeda, maka disepakati anak akan melakukan permainan sepeda minimal 3x dalam 1 minggu dengan teknik interval training, diselang seling masa aktif dan masa istirahatnya. Sebagai contoh selama 5 menit anak bersepeda santai diselingi 2 menit anak bersepeda dengan kecepatan cukup kencang, kemudian diulangi sebanyak 3-4 kali ulangan.

Penatalaksanaan terapi selanjutnya adalah terapi nutrisi. Setelah anak diberikan pendidikan kesehatan terkait food combining dan juga self hypnosis selanjutnya anak diminta menyepakati aturan makan food combining. Pola makan food combining merupakan cara atau pola konsumsi makanan dengan memperhatikan jenis bahan makanan yang selaras sehingga dapat mengoptimalkan pencernaan dan penyerapan zat makanan. Jika anak merasa tidak mampu, anak tidak perlu diberikan paksaan, namun motivasi anak untuk tetap menambah porsi sayur dan buahbuahan. Pelaksanaan terapi hipnosis, aktivitas fisik, dan nutrisi dilakukan secara bersamaan setiap hari. Dimulai dengan penguatan sugesti positif di pagi hari, diulangi terus sepanjang hari dan diterapkan dalam pola makan dan aktifitas harian anak.

\section{PENUTUP}

\section{Kesimpulan}

Terapi HAN (Hipnotis, Aktifitas fisik, dan Nutrisi) merupakan kombinasi yang diusulkan oleh perawat dalam penatalaksanaan masalah obesitas pada anak usia sekolah yang bersekolah di MI Nurul Falah. Terapi HAN melibatkan kemampuan anak mensugesti diri secara positif, meningkatkan motivasi untuk meningkatkan aktifitas fisik dan mengatur makanan yang baik untuk dikonsumsi oleh 
aus, serta menerapkan nya melalui latihan fisik interval training serta food combining.

\section{Saran}

Saran bagi implementasi asuhan keperawatan ini adalah terkait peran keluarga dalam penatalaksanaan obesitas pada anak. Orang tua diharapkan dapat mendukung penyediaan makanan sehat, serta motivator terkait aktifitas fisik anak agar anak mampu merubah pola hidup sehat secara permanen sampai anak dewasa. Kombinasi ketiga terapi ini ditambah dukungan positif dari keluarga khususnya ibu dalam penyediaan makan dan motivator bagi anak diharapkan mampu merubah pola hidup anak menjadi lebih sehat dan sedikit demi sedikit berat badan anak dapat berkurang sehingga tumbuh kembang anak pun menjadi lebih optimal bebas dari risiko penyakit.

\section{DAFTAR PUSTAKA}

ACSM. (2014). ACSM Information on High Intensity Interval Training. ACSM.

Anam, M. (2010). Pengaruh Intervensi Diet dan Olahraga terhadap Indeks Massa Tubuh, Kesegaran Jasmani, hsCRP dan Profil Lipid pada Anak Obesitas.

Barabasz, M., \& Spiegel, D. (1989). Hypnotizability and Weight Loss in Obese Subject. international journal of eating disorders, 335-341.

Brien, S. E., Katzmarzyk, P. T., Craig, L. C., \& Gauvin, L. (2007). Physical Activity, Cardiorespiratory Fitness and Body Mass Index as Predictors of Substansial Weight Gain and Obesity. Canadian Journal of Public Health, 121.

Budiyanti. (2011). Analisis Faktor Penyebab Obesitas pada Anak Usia Sekolah. Depok: tidakdipublikasikan.
Corte de Araujo, A. C., Rosche, H., Picanc, A. R., Leite do, D. M., Ferreira Villares, S. M., de sa pinto, A. 1., \& Gualano, B. (2012). Similar Health Benefits of Endurance and High-IntensityInterval Training in Obese. Plos One Exercise and Juvenile Obesity, 1-8.

Dewantari, N. M., Kayanaya, A. R., \& Melantini. (2011). Perbedaan Perubahan Berat Badan Berdasarkan Frekuensi Senam Aerobik. 68-73.

Gabriel, J. (2008). The gabriel Methode. New York: Atria Books.

Golay, A., Allaz, A. F., Ybarra, J., Bianchi, P., Saraiva, S., Mensi, N., . . . De Tonnac, N. (2000). Similar Weight Loss with Low-energy Food Combining or Balanced Diets. Int J Obes Relat Metab Disord, 492-6.

Green, D., Campbel, L., \& Wallman, K. (2010). Effect of Intermitent Exercise on Physiological Outcome in an Obese Population : Continuous Versus Interval Walking. JSSM, 24-30.

Jones, t. (2010). Fighting Childhood Obesity. ANA.

Keller, K. (2008). Encyclopedia of Obesity. California: Sage Publications,inc.

Kemenkes. (2013). Riset Kesehatan Dasar 2013. Jakarta: Kemenkes.

Kohen, D. P., \& Olness, K. (2011). Hypnosis and Hypnotherapy with Children (4th ed.). New York: Routledge.

La Rocca, J. D. (2009). Childhood obesity : is Parental Nurturing to Blame. IJAHSP, 1-5.

Lebag, E. (2013). Food Combining Itu Gampang : Tubuh Sehat Ideal Walau Makan Kenyang. Bandung: Mizan Pustaka. 
Marsden, K. (2011). The Complete Book of Food Combining. Hachette United Kindom.

NIH. (2014). Exercise \& Physical Activity. Retrieved Maret 03, 2014, from National Institute of health: http://www.nia.nih.gov/health/publicati on/exercise-physical-activity.

OECD. (2014, september 11). Obesity Update 2014. Retrieved from OECD: http://www.oecd.org/els/health-systems/ Obesity-Update-2014.pdf

Ross, R., Janssen, I., Dawson, J., Kungl, A. M., Kuk, J. L., Wong, S. L., . . . Hudson, R. (2004, May 5 ). ExerciseInduced Reduction in Obesity and Insulin Resistance in Women: a Randomized Controlled Trial. Obesity Research, 12.

Sapp, M., Obiakor, F. E., Scholze, S., \& Gregas, A. J. (2007). Confidence Intervals and Hypnosis in Treatment of Obesity. Australian journal of clinical hypnotherapy and hypnosis, 25-33.
Sigal, R. J., Kenny, G. P., Wasserman, D. H., Sceppa, C. C., \& White, R. D. (2006). Physical Activity/Exercise and Type 2 Diabetes: A Consensus Statement From the American Diabetes Association. Diabetes Care, Volume 29 Number 6, 1433-1438.

Tolfrey , K., Campbell , I. G., \& Batterham , A. M. (1998). Exercise Training Induced Alterations in Prepubertal Children's Lipid-lipoprotein Profile. Med Sci Sport Exerc, 1684-92.

White House Task Force on Childhood Obesity. (2010). Solving the Problem of Childhood Obesity within a Generation. New York: Executive Office Og the President of the United States.

Wijayanti, D. N. (2013). Analisis Faktor Penyebab Obesitas dan Cara Mengatasi Obesitas pada Remaja Putri. Semarang: Tidak Dipublikasikan. 